\title{
Hacia una genealogía de la experiencia: La gestión escolar en una escuela de creación (2009-2015)
}

\author{
Gabriela Nacach \\ I.E.S. en Lenguas Vivas “Juan R. Fernández”, ENS 1 y ENS 8 de la Ciudad Autónoma de Bue- \\ nos Aires, Argentina \\ gnacach@gmail.com
}

\begin{abstract}
Resumen $^{1}$
El triunfo de la escuela no es sino el triunfo de una conciencia ética autónoma. El límite anida en nuestra propia experiencia. Este trabajo surge de una praxis educativa en una escuela secundaria de la CABA entre 2009 y 2015. Objetivar la escuela y reflexionar sobre ella nos ayuda a entenderla como un espacio donde se despliegan multiplicidad de dimensiones que desafían la práctica cotidiana y nuestra subjetividad docente. Subyace en este escrito la pregunta por el conocimiento, por lo que se aprende en la escuela, por las otras formas de aprender, por los modos de enseñanza, por la relación siempre conflictiva entre "lo establecido" en la dinámica escolar (las normas, los espacios, los mecanismos burocráticos, los rituales escolares) y la novedad, por el rol -político- que asumimos cotidianamente los y las educadoras, por la gestión institucional. Me interrogo, también, por la autoridad, la autonomía y la transgresión y las formas de validar o contrastar las verdades educativas, por la construcción cultural e histórica de los actores que transitan la escuela y su importancia real dentro del proceso escolar. Intento finalmente posicionarme críticamente frente al propio desempeño, presentándome pero también re-presentándome, desnaturalizando mis propios supuestos y optando, nuevamente, por la educación pública.
\end{abstract}

Palabras clave: Dinámica escolar, gestión educativa, educación pública, vigilancia epistemológica

Towards a genealogy of experience: Educational management in a newly created school (2009-2015)

\begin{abstract}
The triumph of the school represents the triumph of an autonomous ethical conscience. The limit nests in our own experience. This work arises from an educational praxis in
\end{abstract}

1 Una versión preliminar de este trabajo fue presentada como memoria profesional en la asignatura Didáctica Especial y Prácticas de la Enseñanza de la Antropología en 2016. 
a high school in Buenos Aires between 2009 and 2015. Reflecting on the school helps us to understand it as a space where a multiplicity of variables that challenge our daily practice and our subjectivity as teachers are displayed.

Underlying this writing is the question about knowledge, about what is learned in school, about other forms of learning, about teaching methods, about the always conflicting relationship between "the established" in school dynamics (norms, spaces, bureaucratic mechanisms, school rituals) and the novelty, for the political-role that educators assume daily, for institutional management. I ask myself, also, about the authority, the autonomy and the transgression and the ways of validating or contrasting the educational truths, for the cultural and historical construction of the actors who pass through the school and their real importance within the school process. I finally try to position myself critically in front of my own performance, presenting myself but also re-presenting myself, denaturing my own assumptions and opting, again, for public education.

Keywords: School dynamics, educational management, public education, epistemological surveillance

\section{Vigilar y construir}

... la epistemología de la política educativa es un enfoque/esquema que permite el análisis de la producción de conocimiento del campo; no es en sí misma un posicionamiento, sino el modo de analizar los posicionamientos en términos del propio investigador como esquema facilitador para llevar a cabo la práctica de la vigilancia epistemológica y en segundo lugar para llevar a cabo estudios epistemológicos en política educativa.

\section{Cesar Tello}

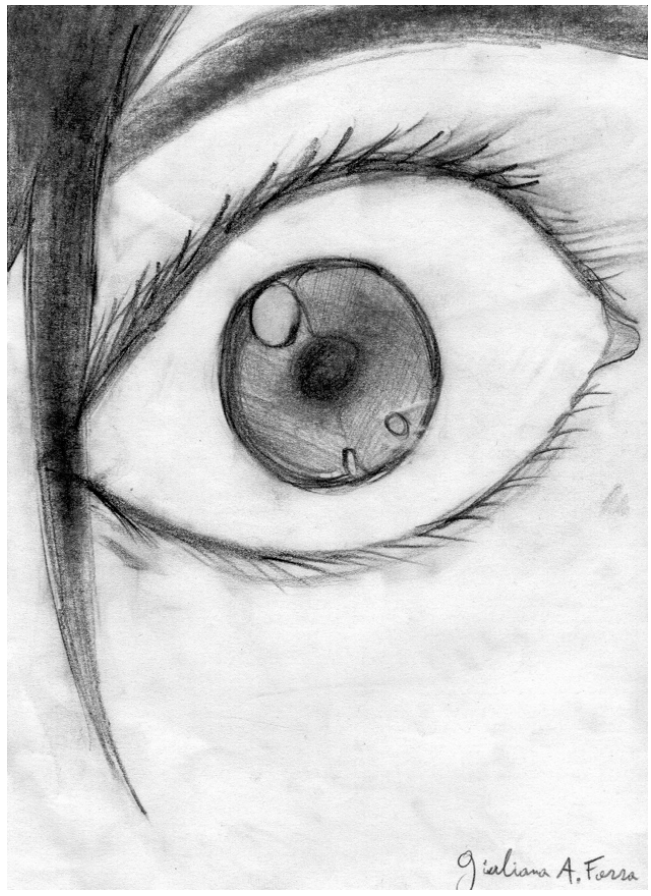

Imagen 1. Tapa del boletín institucional n 4, 2014 
No todos los días tenemos la posibilidad de formar parte de una escuela de creación. Soy docente de una escuela secundaria de gestión pública del barrio de Villa Crespo en la Ciudad de Buenos Aires desde el mes de abril de 2009, año de su creación. ${ }^{2}$

Suele ocurrir que, en la dinámica de los espacios pedagógicos, siempre contingentes, una suerte de inercia de la vida cotidiana obture la posibilidad de reflexionar sobre lo que hacemos a diario desde nuestro rol de educadores y educadoras. Se torna complejo, aunque no imposible, convertir lo familiar en exótico, posicionarnos desde la extrañeza (Neufeld y Wallace, 1999). Sin embargo, elijo realizar este escrito tomando como epicentro esta institución y no otras por las que he pasado en mi trayectoria en el campo educativo porque considero que mi estar siendo docente, parafraseando a Rodolfo Kusch, nació entre las paredes y escombros de este edificio derruido del barrio de Villa Crespo. En este sentido, creo encontrar en esta experiencia formativa muchas de las huellas de mi definición profesional actual y mi ferviente decisión de seguir optando por la educación pública. Ejercitar la vigilancia epistemológica (Gouldner, 1979, cit. por Neufeld y Wallace, 1999) exige reflexionar sobre la construcción y reformulación de las identidades docentes. De una u otra manera, este texto contiene supuestos y formulaciones más o menos explícitas, tramas visibles o invisibles que han tejido una mirada sobre la educación, sus alcances y su realidad.

No es posible sustraerse, para el análisis, del contexto general en el que nos encontramos. Nos es necesario distinguir, en principio, escalas y responsabilidades que, finalmente y en función de cualquier recorte analítico que se realice, se reflejan en las aulas, en todas las aulas. Los niveles macro y micropolíticos son necesarios para pensar en cómo el Estado, a través del dispositivo escolar, concibe y crea subjetividades a partir de una instrumentación compuesta más de elementos y fragmentos que de discursos y prácticas uniformes y coherentes (Foucault, 1975). Es cierto que me detendré en un espacio micropolítico - una institución, unas aulas, unos y unas jóvenes-, sin embargo, pongo sobre la mesa la imposibilidad de repensar la reflexión que aquí me convoca fuera de un contexto sociopolítico, laboral y profesional más amplio. ${ }^{3}$

En este aspecto, concebir estrategias de lucha para transformar una realidad instituida (Tenti Fanfani, 2012) requiere de una base sobre la que proyectarse, base que solo puede ser una explicitación coherente y unitaria del pasado en su relación con el presente y el futuro (Narotzky, 2004: 125). Los movimientos pendulares respecto de las políticas educativas y el rol de la escuela en la construcción de la subjetividad han sostenido en distintos momentos multiplicidad de verdades posibles -en muchos casos diametralmente opuestas entre sí- acerca de lo que la escuela y el docente deben hacer. Siguiendo a Narotzky (2004: 125):

Cualquier filosofía verdaderamente crítica de la historia va a tener que plantearse la historia como simultáneamente un proceso de heterogeneización y un proceso de homogeneización, es decir, un proceso en el que se construyen conciencias del mundo diferentes y conciencias del mundo totalizadoras al mismo tiempo.

2 La progresiva implementación de la Nueva Escuela Secundaria (NES) corresponde a un análisis que de tan complejo ameritaría otro artículo. Solo decir que en 2016 sucesivos cambios en la gestión institucional de la escuela y la adecuación curricular para la elaboración del Plan Curricular Institucional en consonancia con los nuevos diseños significó una ruptura que en alguna medida fue la ruptura de un proyecto educativo.

3 En el mes de febrero de 2017, el entonces Secretario de Gestión Educativa del Ministerio de Educación y Deportes de la Nación, Max Gulmanelli, ocupó un rol central en lo que fue la reestructuración de dicho ministerio que implicó la desaparición de la Dirección Nacional de Gestión Educativa y, con ella, las direcciones de nivel -entre otras, la de nivel secundario-y las coordinaciones de modalidad. Una importante política de descentralización fue acompañada, en la CABA, por la implementación de la NES y la "Secundaria del Futuro", con enormes consecuencias en la organización pedagógico-didáctica y el trabajo docente. 
Por ello, es importante ser capaces de observar, describir y analizar los procesos a la vez materiales y simbólicos que constituyen las diversas historias que nos configuran como educadores y educadoras en un tiempo determinado. De aquí, politizar el debate sobre la educación pública supone destacar el papel que ella tiene en la sedimentación de un orden cultural futuro (Carli, 2003). Rememorar y reconstituir en sentido, comprender y problematizar, reconocernos como parte de diversas herencias, permite volver los pasos sobre una mirada de la educación como disputa, poder y conflicto. La escala microscópica e institucional, propia del recorte antropológico, pone sobre la mesa de dimensión humana de la educación, finalmente, "los contenidos y los sentidos, generalmente contradictorios, de relaciones y procesos sociales en los que se involucran sujetos particulares" (Rockwell y Ezpeleta, 1985).

Por último, no pretendo con este trabajo otra cosa que recuperar una experiencia, entendiendo que se trata de un ensayo preliminar que no agota la discusión y que podría profundizarse en un análisis posterior, tomando particularmente uno de los tantos aspectos/dimensiones que en estas páginas se mencionan. Por lo mismo, la bibliografía utilizada, así como las citas de autores y autoras, no buscan ser exhaustivas, sino que confluyen con un estilo de escritura decididamente más narrativo -que se podría ajustar más a una crónica- que académico. De esta forma, los conceptos se entrelazan con imágenes y relatos en primera persona. Quizás este sea el aporte más significativo de un trabajo cuyo objetivo es poner en valor la educación pública sin dejar de presentar sus tensiones, en un contexto -este artículo fue escrito a mediados de 2019 y en ese contexto se enmarca- signado por un fuerte ataque que los propios Estados, nacional y jurisdiccional, encabezan.

\section{La melancolía: un signo de este tiempo ${ }^{4}$}

Solo me conformaría con ser una gota de sudor de Sarmiento.

Esteban Bullrich, Ministro de Educación y Deportes de la Nación, en “Animales Sueltos”, América TV, julio de 2016

La escuela vive hoy un momento transicional muy grande, y esta circunstancia -vinculada específicamente a un cambio de gestión a nivel nacional y una profundización de una política educativa en la Ciudad de Buenos Aires- parece forjar una mirada apocalíptica, un clima personal, existencial y social, una melancolía similar a ese "mal de frontera", definida en el siglo XVI como "una enfermedad de la transición y del trastocamiento [...] asociada a la vida frágil de gente que ha sufrido conversiones forzadas y ha enfrentado la amenaza de grandes reformas y mutaciones" (Barra, 2001: 31, cit. por Romero, 2009: 20).

La escuela secundaria parece transitar un mal de época, una transición profunda y sostenida que sacude los propios cimientos políticos, ideológicos, las convicciones más profundas; las expectativas y proyecciones de futuro de nuestros y nuestras jóvenes. Parecerá contradictorio con la apuesta cotidiana por la educación en distintos niveles de análisis y los intentos exagerados por "hacer del aula nuestro territorio", pero ocurre.

4 Este trabajo fue presentado para su publicación a la convocatoria IICE en abril de 2019. Intentaba ser un espacio de reflexión y discusión que al mismo tiempo cuestionara las políticas educativas que se venían desarrollando a nivel nacional desde la asunción de Mauricio Macri en diciembre de 2015 y en la Ciudad de Buenos Aires desde 2007 y con una profunda virulencia a partir de 2016 en la gestión de Horacio Rodríguez Larreta. Hacia noviembre de 2019, el contexto nacional parece volver a redefinirse y es importante tenerlo en cuenta para contextualizar lo que en estas páginas se comparte. 
Asistir cotidianamente al desmantelamiento de la educación pública y el corrimiento del Estado como garante de derechos no supone de ninguna manera dejar de buscar mecanismos de resistencia que nos permitan encontrar fisuras o líneas de fuga ante la inminencia de cambios estructurales del sistema educativo.

\subsection{La opción por la escuela pública}

¿Qué significa optar hoy por la escuela pública? ¿Qué supone ser consciente de su gestación y repensar su devenir? Mucha tinta se ha vertido sobre el rol privilegiado que tuvo la institución escolar en la producción y reproducción de una identidad nacional y unos ciudadanos nacionales; otra tanta -más reciente- presenta la educación y la escuela en su interior como espacio de conflicto y de disputa por los significados (Rockwell, 2011; Rockwell y Ezpeleta, 1985, entre otros). Defino así esta opción como una suerte de fractura. Escuela pública, añorada y cuestionada, la causante de todos los males y la única capaz de reparar esos mismos males (cf. Grimson y Tenti Fanfani, 2014), vieja y nueva a la vez, disciplinadora y transformadora, objeto histórico y objeto con dimensión de historicidad que debe analizarse con claves de lectura del presente (Carli, 2003: 17). La educación en general y las instituciones escolares en particular se mantienen en un frágil equilibrio entre el pasado y el presente: las viejas estructuras persisten en nuevos escenarios, las subjetividades homogéneas, históricas y ahistóricas, chocan de frente con la alteridad, con la irrupción de la diversidad, de las múltiples diversidades (étnicas, sexo-genéricas, lingüísticas, culturales, de clase). Para cualquier docente el trabajo con adolescentes y jóvenes no se debería dejar de pensar sin estas diferencias. Por definición, "los nuevos resultan extraños para los responsables de su acogida". Y en muchos casos, además, "suelen ser percibidos como hostiles, cuando no peligrosos" (Kantor, 2008: 16-17).

Optar por la escuela pública hoy es, más que nunca, creer en su valor intrínseco, con todas sus contradicciones y transformaciones a cuestas. Esta creencia, más situada que nunca, se basa en el rol del Estado como garante de derecho a través de una política educativa, pero también en el docente como sujeto político que debiera poder ejercitar, cotidianamente y con las contradicciones inherentes a la historicidad de su práctica, una filosofía de la praxis, una relación consciente entre pensamiento y acción (Gramsci, 2003). El triunfo de la escuela no es sino el triunfo de una conciencia ética autónoma. Si la escuela es "lo que hay" requiere de ingenio, de volver a pensar, de revisitar (Nicastro, 2006). Si la escuela es "lo posible", tenemos que tender a encontrar "lo mejor dentro de lo posible". La escuela es esperanza y es utopía, que ya no puede considerarse como la creencia en el advenimiento necesario del ideal al término mítico de la historia, sino como la modalidad de su advenimiento posible en el tiempo (Mosès, 1992).

En un contexto nacional signado por una triste y angustiante vuelta al pasado, quizás sea momento de pensar en la escuela, en el aula, como la última alternativa para que la educación pública se convierta en el principal espacio político y cultural en el cual refundar los horizontes de la Argentina (Carli, 2003: 23; 71). En este sentido necesitamos re-posicionarnos frente a un embate actual del pasado sobre el presente que parecíamos ir dejando atrás y que nuevamente nublaba nuestras expectativas respecto de las herramientas que debiera llevar consigo la institución escolar para construir una sociedad más justa e igualitaria (Grimson y Tenti Fanfani, 2014). 


\section{La unidad de análisis}

Haremos referencia en este trabajo a un bachillerato orientado en artes y medios de doble jornada que nació en la Ciudad de Buenos Aires hacia fines de marzo de 2009. Está ubicado -como ya hemos anticipado- en pleno barrio de Villa Crespo. Una resolución firmada por el entonces Jefe de Gobierno porteño Mauricio Macri aprobaba la creación de una Escuela de Expresiones Culturales. Fue así diseñada como un espacio de formación de un determinado tipo de perfil de artista y comunicador, más ligado al establishment que a una visión del arte y los medios como herramientas para la transformación social. No obstante esto, una serie de conjunciones hicieron posible un equipo directivo con una amplia trayectoria y una mirada sobre la educación por lo menos novedosa. Mesas de trabajo ampliadas con coordinadores y coordinadoras, parejas pedagógicas, fuerte relación con la comunidad y las familias y muchas otras iniciativas hicieron de la tarea de educar algo verdaderamente sugestivo y transformador.

Todas las discusiones que aquí entable deben entenderse como la ardua tarea de conocer ese algo que se critica, en tanto este conocimiento intenta devenir como insoslayable praxis de transformación de lo real que muchas veces se erige como incuestionable (Neufeld y Wallace, 1999).

\section{1. "En obras"}

"En marzo de 2009 nos encontramos con una estructura vacía de horizontes, de habitantes, de planes, de sueños, de posibilidades.... Esta frase junto a la siguiente fotografía, fue la que inició la primera jornada institucional en junio de 2009.

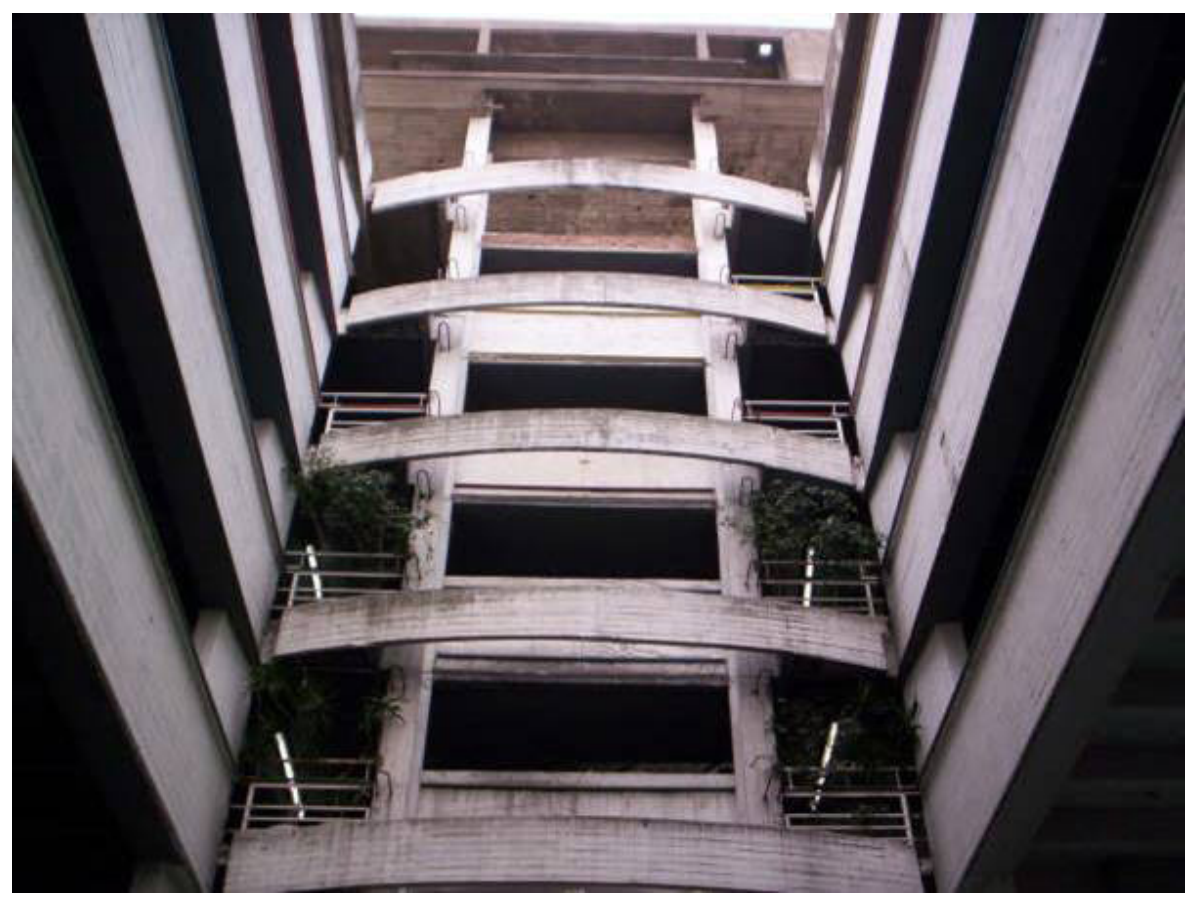

Imagen 2.

Esta imagen refleja el escenario cotidiano por el que transitábamos. La escuela siempre estuvo en obra. Fue la lucha de la comunidad educativa la que, año tras año, lograba ir construyendo los pisos necesarios para albergar a los y las jóvenes que iban llegando. 
Las obras nunca se hicieron en temporada estival, comenzaban a mediados de abril, y a medida que llegaban los operarios y albañiles notaban cómo lo realizado el año anterior debía ser subsanado: los pisos se levantaban, las puertas no cerraban, conexiones mal realizadas nos dejaban sin gas y sin luz alternativamente, cuando no un corto circuito convertía en posible tragedia un primer día de clases.

En la actualidad, la escuela sigue en obra, aunque se haya anunciado el "fin de obra" en más de una oportunidad. En octubre de 2015, el entonces Ministro de Educación de la Ciudad de Buenos Aires, Esteban Bullrich, se comprometía a recomenzarla y terminarla a partir del día siguiente de la firma de un acta con autoridades y estudiantes, una semana antes de las elecciones a Jefe de Gobierno porteño.

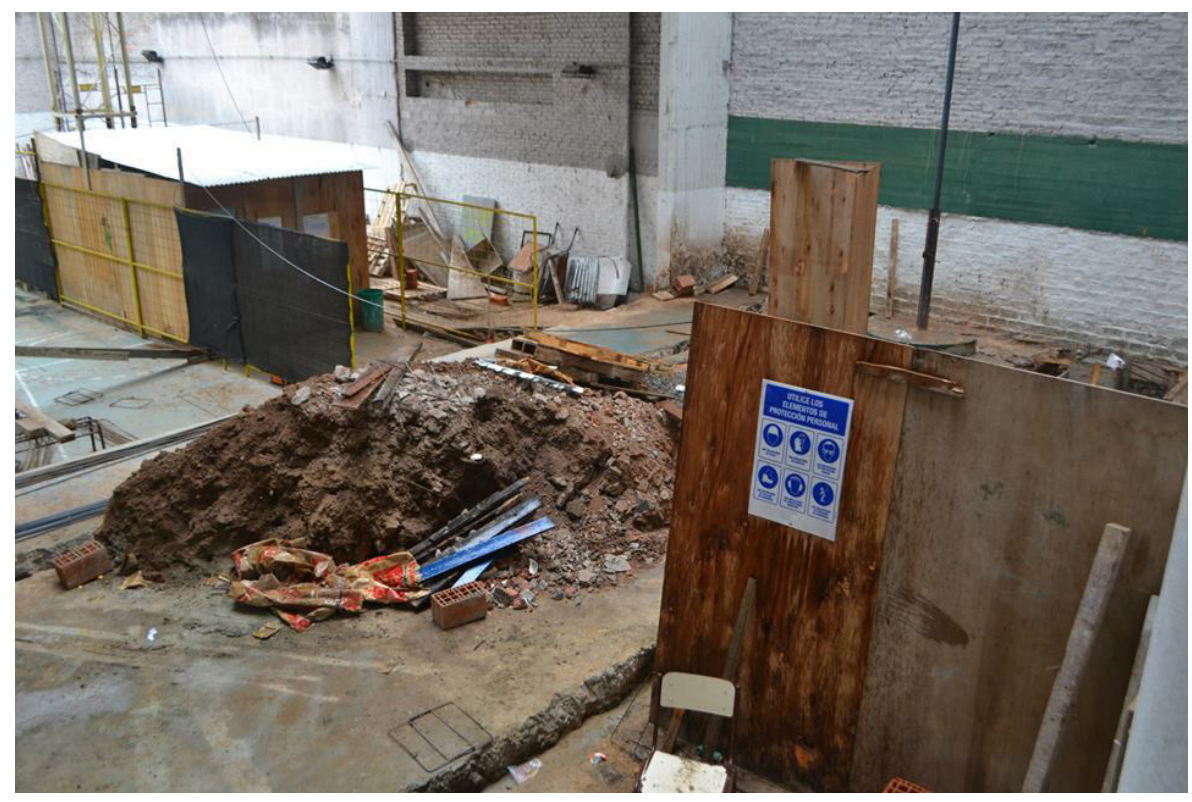

Imagen 3. "En obras". Registro fotográfico de los trabajos de ampliación de la E.E.M 3 D.E 7. https://obratresdelsiete.wordpress.com/

Taller Integrador de Medios. 2014.

En abril de 2019, momento en que se escribía este trabajo y más de tres años después, seguíamos aguardando.

El tema de la obra no resulta un dato menor para la vida cotidiana de la escuela y de alguna manera expresa, también, decisiones macropolíticas. La doble jornada con solo dos cursos por año y algunas otras variables han hecho de ella, probablemente, una escuela inviable para una concepción de la educación que se mide en términos de costo-beneficio y rentabilidad. A la realidad en materia de infraestructura se le suman las reiteradas negativas a ampliar la planta orgánica funcional y todos los años se emprenden arduas negociaciones para contar con horas de Plan de Mejora Institucional y Fortalecimiento. Si lo que en la actualidad parece ocurrir es que el nivel de autonomía pedagógica depende más de decisiones político-institucionales que de un sistema que busque romper el círculo de la desigualdad (Dussel et al., 2007), no podemos olvidar el lugar que ha decidido ocupar el Estado en estas últimas tres gestiones del GCBA en relación con la escuela pública. Cuando prima un interés fiscal, velado por discursos de autonomía y autorregulación institucional, lo que sucede es, o bien falta de acompañamiento a quienes más lo necesitan y por ende mayor desigualdad, o bien ausencia de recursos necesarios para continuar un proyecto educativo que pueda sustentarse en lo pedagógico (Grimson y Tenti Fanfani, 2014). 


\title{
3.2. La metáfora del barco
}

Los dioses habían condenado a Sísifo a empujar sin cesar una roca hasta la cima de una montaña, desde donde la piedra volvería a caer por su propio peso. Habían pensado con algún fundamento que no hay castigo más terrible que el trabajo inútil y sin esperanza.

\author{
Albert Camus 6 \\ Solamente aquel que construye el futuro tiene derecho a juzgar el pasado. \\ Friedrich Nietzsche ${ }^{7}$
}

Si retomamos la idea expuesta de que la escuela es "lo que hay", si volvemos a la melancolía como "mal de frontera" y si, finalmente, seguimos apostando -muy a pesar de los vaivenes políticos- por el rol del Estado en la definición de políticas públicas que garanticen los derechos educativos, es quizás esta misma idea de liminalidad y porosidad de las fronteras la que nos permitirá sostener una mirada que trascienda ideas de decadencia que parecen instalarse en los sentidos sociales. Repensar la escuela y las decisiones políticas en su interior es comprender que, en algún punto, la gestión institucional es la organización de lo posible y en un punto imprevisible (Nicastro, 2006), al mismo tiempo que entendemos que gestionar es hacer que las cosas sucedan. "Lo que hay" -la institución y su organización-, finalmente y nuevamente, es producto de una operación que se inscribe en el tiempo histórico y en el accionar político (Nicastro, 2006). Esquivar la museologización de la escuela supone enmarcarnos en un mundo sin certezas, retomando a Larrosa (2014), en el "principio de incertidumbre". Fue tal vez este principio el que animó al equipo de conducción que se hizo cargo de la creación de la escuela a abandonar el diseño primigenio y mínimo propuesto por la Dirección de Media y utilizar la metáfora del barco: una nave que emprendía un camino incierto y que animaba a sus tripulantes (padres y madres que inscribían a sus hijos en un edificio inhóspito con vidrios rotos, un solo piso habilitado y una plaga de palomas que no reconocía estación del año) a confiar en un equipo capacitado para llegar a buen puerto (aunque a ciencia cierta no se sabía cuál era, y si realmente había un puerto donde arribar). El equipo de conducción ampliado, formado por el equipo directivo, la asesoría pedagógica y las coordinaciones de área, comenzó a delinear el proyecto de la gestión institucional, que puede sintetizarse en

la forma de organizar el trabajo escolar [...] los modos en que se deciden las cosas y el tipo de decisiones que se toman [...] el diseño del tiempo y el espacio [...] la conformación de los grupos [...] el tratamiento de los conflictos [...] las normas y las sanciones [...] los intercambios comunicacionales. (Romero, 2009: 24)

Entre las metas propuestas por la escuela se encontraban, entre otras, reconfigurar tiempos y espacios, enfatizar las preguntas, más allá de las respuestas, convertir a la escuela en un lugar donde equivocarse y reposicionar al docente como un adulto que es capaz de convertir lo posible en probable y esto en realidad (Jornada de reflexión Proyecto Escuela, junio de 2009).

Una gestión que se presentaba y representaba como "de puertas abiertas", democrática y transformadora. Una gestión educativa donde el lugar de la palabra dejaba a la luz espacios menos burocráticos y acartonados, más flexibles, más abiertos. Una gestión que desafiaba la gramática escolar (Dussel, 2007: 13) que de una u otra manera persiste

6 Jornada de reflexión Proyecto Escuela, junio de 2009. SACAR NOTA 6.

7 Estas dos frases formaron parte de la primer Jornada de reflexión Proyecto Escuela, junio de 2009. 
en las instituciones "ya sea por una especie de fuerza de inercia, ya sea porque logran adaptarse a situaciones nuevas" (Halbwachs, 1938: 5). Así, la definición del incipiente Proyecto Educativo Institucional (P.E.I.; hoy P.C.I.) contemplaba parejas pedagógicas, aulas por áreas, rol de coordinaciones como mediadores reales de la propuesta educativa, proyectos institucionales (las efemérides y los actos escolares como espacios de construcción conjunta del conocimiento sobre la historia), la elaboración con la comunidad escolar del código de convivencia, un fuerte vínculo con las familias y la cooperadora y una proyección de obra que permitiera, en línea con la resolución 93/09 del Consejo Federal de Educación, convertir la escuela secundaria en un espacio inclusivo y significativo, a partir de diferentes estrategias, diversas formas de estar y aprender y reconociendo las trayectorias escolares reales de los estudiantes. La escuela como laboratorio, como comunidad de aprendizaje, como sitio privilegiado para la transformación social a partir del arte y los medios como herramientas para lograrla.

La cotidianeidad escolar se componía de esta forma de momentos singulares, un "concreto real" en el cual la normatividad y el control estatal -en este caso del GCBA y de la supervisión- se hallaban presentes pero no necesariamente determinaban la trama de relaciones y los sentidos que iba progresivamente adquiriendo la escuela (Ezpeleta y Rockwell, 1985). Con solo 60 estudiantes de $1^{\circ}$ año y no más de 20 docentes con distintos perfiles y recorridos, nos permitíamos pensar, a partir de una mirada histórica de la escuela secundaria, propuestas alternativas vinculadas con un movimiento histórico real (Ezpeleta y Rockwell, 1985).

Retomando a Romero (2009: 26), la gestión como gesta supera una visión meramente técnica de la gestión para transformarse en un campo básicamente político y profundamente vital. Desde una mirada retrospectiva, es probable que la invitación a fecundar con nuevos sentidos el "hacer escuela" que tuvo el equipo de conducción en 2009, fuera paulatinamente dando lugar a una dimensión de heroicidad, a la creencia de estar militando en pos de una hazaña cultural (Romero, 2009). Muy en sintonía con el movimiento histórico-político y cultural que estaba viviendo nuestro país, lo "no dicho" o "dicho a medias" ganó espacios, hizo ruido y en alguna medida minó las bases primeras de una práctica institucional verdaderamente novedosa.

Transitar nuevas identidades en la escuela secundaria no es un camino sencillo. Es probable que la necesidad de "dejar una huella personal" (creación como parición, como nacimiento e identidad última) colisionara con un proyecto colectivo en el que muchos y muchas creíamos y que sosteníamos cotidianamente a pesar de los embates de la política educativa jurisdiccional. Lejos de focalizar en las subjetividades individuales, la idea aquí es intentar elucidar hasta qué punto y en qué medida "una historia diferente (de la hegemónica) pesa realmente sobre la actividad práctica individual y colectiva" (Narotzky, 2004: 135); en qué medida una propuesta novedosa fluctúa entre la conformación colectiva de una concepción del mundo, un proyecto político-educativo y la acción individual. La creencia de fuertes liderazgos con grandes personalidades que posibilitarían la radicalidad de los cambios aparecía en escena.

Con todo y desde la distancia, se forjó una clara identidad que nos definió como institución y colectivo y a partir de la cual, más allá de las disidencias, dimos pelea en momentos nada fáciles para la continuidad de las políticas institucionales. El marco aún era un marco común: los y las jóvenes, el sostenimiento de su escolaridad y la reinvención de la escuela bajo nuevas formas, "más saludables, más equitativas y sobre todo más cercana a la vitalidad y la alegría que produce educar a las nuevas generaciones" (Romero, 2009: 39).

Interrogarnos por las claves de la gestión es preguntarnos por cómo imaginar nuevas herramientas y modos de hacer las cosas que generen las condiciones institucionales 
y pedagógicas para un conocimiento verdaderamente situado. Si, siguiendo a Terigi (2004: 193), "la enseñanza 'se sabe' política" y "asume la responsabilidad social de lograr que todos los que asisten a las escuelas en calidad de alumnos alcancen las metas educativas que se consideran valiosas para el conjunto de la población", la gestión institucional, que se expresa en la forma en que se organiza el trabajo escolar (Romero, 2009) se encuentra hoy con el gran desafío de definirse (democrática, transformadora, expulsora) en tanto esos mecanismos y dispositivos escolares impactan directamente en la producción de una determinada subjetividad.

Nada sencillo, dado que no se trata de otra cosa que de una escuela media "estallada", "fragmentada", "jaqueada" por las demandas externas (Dussel et al., 2007), aquejada por la "pérdida de sentido" (Tenti Fanfani, 2003), interpelada por la "extrañeza" de las juventudes (Kantor, 2008) y receptora de realidades diversas que desafían la hibridez de un mundo adulto que se desequilibra entre la necesidad de restituir viejos límites y la angustia de la libertad, que implica, básicamente, saberse inconsistente, contradictorio, inmaduro, incoherente, político.

\subsection{La pareja pedagógica}

Cuando nuestros ancestros se pusieron en pie, liberaron las manos, que de alguna manera se forman y deforman gracias a la inteligencia. En labores como las artesanales persiste la simbiosis de mano y conciencia, que se divorcian en la producción masiva. La grandeza de las manos fue menospreciada desde la perspectiva soberbia de las clases dominantes, cuando olvidaron que las manos vencen la resistencia de un material, tocan, exploran, escriben, expresan con dibujos o sonidos, crean objetos y son el inicio de los instrumentos y de las tecnologías y máquinas más sofisticadas.

María Rosa Palazón Mayoral, 2006

Una frase, la de Mayoral, que bien podría adjudicársele a Benjamin en La obra de arte en la era de su reproductibilidad técnica. Da pie a la pregunta acerca del conocimiento "seriado" y la pérdida de unicidad, de originalidad, en definitiva, a la sustitución de los momentos únicos e irrepetibles por una constitución rutinizada de la labor. ¿Cuánto de esto hay en la docencia? ¿Cómo repercuten nuestras condiciones de trabajo y la construcción de nuestras subjetividades en el acercamiento a los otros y otras (sean estudiantes, sean padres o madres, sean otros y otras docentes)? Un borrador del P.E.I del año 2009 afirmaba:

Al igual que como sucede con los chicos, la escuela pública debe por definición albergar a todo aquel que pueda trabajar en ella. Queda como desafío, en el marco del trabajo cotidiano, encontrar los mecanismos en que estas diversidades -en lo personal, cultural, teórico, metodológico, pedagógico, etc.- encuentren el cauce adecuado para transitar por la institución desarrollando y articulando sus saberes a partir de una perspectiva co-dialógica que incluya todas las escalas, instancias y jerarquías que se encuentran dentro de la misma. (Borrador Proyecto Escuela, noviembre de 2009)

En este marco nace la figura de la pareja pedagógica, entendida como un espacio abierto a la pluralidad epistemológica -en general, los y las docentes proveníamos de diferentes campos disciplinares- $\mathrm{y}$ a la posibilidad de que los estudiantes pudieran observar e interpretar la realidad desde diferentes y complementarios marcos teóricos y epistémicos. Trabajar con otros y otras es un desafío, pero trabajar con otros y otras que uno no ha necesariamente elegido a lo largo de muchos ciclos lectivos es un desafío aún mayor: aprendizaje, roces, desequilibrios en los roles, formas de trabajo disímiles, niveles de compromiso, etc., hacen que muchas veces desestimemos el valor de la apertura epistémica por el agotamiento que implica su sostenimiento. ¿Cuánto hay, además, de un acompañamiento concreto de la gestión? ¿Cuánto de ese acompañamiento es posible? 
El camino no fue fácil. Los docentes, al igual que el resto de los actores de la comunidad educativa, no son uniformes, mutan y se dinamizan frente a realidades en profunda transformación. En este sentido, es necesario advertir una tensión entre la identidad "prescripta" y la identidad "real" de los docentes (Dussel et al., 2011). Lejos del equilibrio, las trayectorias docentes se manifiestan como disímiles en muchos aspectos: formación, actualización, especialización, a lo que se agrega la subjetividad de los actores: sus propios intereses, los criterios construidos en torno a lo que podríamos llamar la responsabilidad de educar, las formas de trabajar con otros y otras, el posicionamiento ético-político frente a la tarea, la capacidad de poder responder a la coyuntura y los cambios que presentan los y las estudiantes y sus familias a través del tiempo, entre otros.

Con el tiempo fuimos rediseñando lo que en un primer momento aparecía como precepto: el sostenimiento de la pareja pedagógica en aulas de 50 estudiantes. La multimodalidad según el grupo y los acuerdos que íbamos tejiendo a lo largo de los años se convirtió en una estrategia interesante para dar continuidad a un proyecto, en principio, valioso. Vuelve a tornarse necesario detenerse para revisitar los espacios, redimensionarlos y resignificarlos en función de las necesidades puntuales y los grupos por los que nos toca atravesar como equipos de trabajo.

\subsection{El conocimiento y los sujetos de enseñanza}

Es incapaz de experiencia el que se pone, o se opone, o se impone, o se propone, pero no se expone. Es incapaz de experiencia aquél al que nada le pasa, a quien nada le acontece, a quien nada le sucede, a quien nada le llega, a quien nada le afecta, a quien nada le amenaza, a quien nada le hiere

Jorge Larrosa, 2014

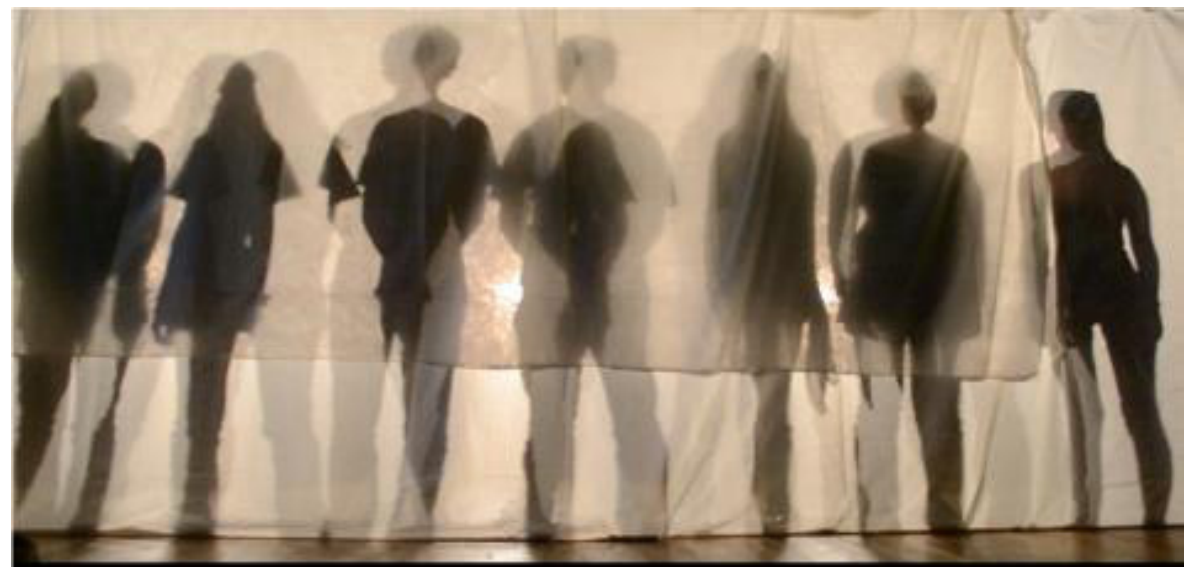

Imagen 3. Acto conmemorativo a la "Noche de los lápices", 4 año, 2012

\subsubsection{Juventud desmesurada}

El sujeto pedagógico moderno es imperfecto, afirma Puiggrós (1994: 57). Efectivamente, y por suerte,

no solamente graba los mandatos sino que los decodifica, desordena y transforma [...] escapa al principio filicida propio del paradigma en el cual se inscribe, una de cuyas finalidades es hacer rutinario al sujeto, para la perpetuación de las viejas generaciones y el orden establecido. 
Los enfoques pedagógicos que escapan al designio normalizador propio de una lógica estatal que sentó las bases para la expansión de la civilización y desnaturalizan concepciones estigmatizantes y homogeneizantes de la juventud, son los más interesantes para pensar en nuestros sujetos de enseñanza. La adolescencia -síntoma de la falta-, el alumno -tabula rasa a ser llenada por el mundo adulto- da progresivo paso a las juventudes en plural, signo de la heterogeneidad y de las disímiles construcciones de subjetividad (v.g. Margulis, 2008). La normatividad que establece el "deber ser" y sustenta el modo en que se califica y se clasifica a los sujetos, la norma impuesta que deviene en proscripción (Kantor, 2008) se desvanece en otra escala, donde los contenidos y los sentidos se presentan generalmente contradictorios, una escala de relaciones y procesos sociales en los que se involucran los sujetos particulares (Ezpeleta y Rockwell, 1985). Frente a una mirada que únicamente caracteriza al maestro como agente de la reproducción social, la reconstrucción de la escala cotidiana permite ver cómo los y las jóvenes discuten y evidencian los procesos estructurales, los puntos de coerción que cierran salidas y los momentos de consenso que abren alternativas (Rockwell, 2011: 27).

Así como existen disímiles criterios de clasificación y principios de diferenciación, distintas valoraciones y representaciones de los estudiantes en general y de cada grupo en particular (la misma clase es señalada por un docente como disruptiva y por otro como entrañable), también están presentes las actualizaciones subjetivas de los sujetos concretos de la enseñanza -los y las jóvenes- quienes interiorizan los esquemas culturales vigentes pero no se limitan a repetirlos como autómatas (Padawer, 2010: 355). El proceso de resistencia de los jóvenes y su "intento de empujar las fronteras simbólicas de esa gramática [escolar] para constituir una nueva identidad como alumno que incluya gestos y símbolos juveniles" (Montesinos et al., 2009: 7) choca con los intentos denodados de muchos docentes de "traducir" al "extraño". A los múltiples extraños, extrañas y extrañes, ${ }^{8}$ en algún punto y cada vez más, "intraducibles". Por eso, echar al cuerpo adolescente una mirada que no lo vuelva extraño, que lo constituya como otro a quien y con quien hablar, "plantea el problema del lugar preparado a los recién llegados en la institución de lo social" (Cornu, 2003, cit. por Kantor, 2008: 17).

La construcción del conocimiento entendida como apropiación de los significados (Candela, 2001; Padawer, 2010) pone sobre la mesa la discusión por la cultura y la cultura de los otros y las otras y la pregunta por el conocimiento escolar y las formas en que este se transmite. En tal sentido, es cierto, por una parte, que quienes detentan el poder dentro del campo escolar, en un momento determinado "colocan en posición dominante en el sistema de arbitrariedades culturales es aquella que expresa más completamente, aunque casi siempre de forma mediata, los intereses objetivos (materiales y simbólicos) de los grupos o clases dominantes" (Bourdieu y Passeron, 2001: 23, prop. 1.2.3). Pero, por otra parte, no es menos cierto que la construcción del conocimiento "es un proceso social que moviliza prácticas de creación conjunta de la cultura” (Bruner, 2001, cit. por Rúa, 2016: 110).

Todas estas discusiones se cristalizan en el "territorio", el "barro" del "entre muros" cotidiano, reflejo de los permanentes acuerdos que se tejen entre docentes y alumnos y alumnas. Acuerdos que marcan cierta fragilidad, toda vez que los intersticios permiten el quiebre y la subversión del orden establecido, representado por la autoridad docente. Lo cotidiano es la ruptura, no la rutina. La interminable interrupción. La complicidad

\footnotetext{
8 En el momento en que este trabajo fue pensado, la multiplicidad de formas de identificación de género que existen en la actualidad aún no estaba tan presente en las escuelas. En este sentido es importante decir que el uso del lenguaje inclusivo quizás deba comenzar a formar parte de escritos o ensayos académicos. No utilizarlo en este escrito no significa no tener en cuenta la necesidad de visibilizar esta realidad a todas luces disruptiva para la gramática histórica.
} 
y el respiro e inmediatamente el "ruido" (Rockwell, 2011). El aula se convierte en un lugar privilegiado para entender la reproducción, pero también la complejidad propia del mundo social.

En estas negociaciones, el sujeto de la formación no es solo el sujeto de aprendizaje, si entendemos ambos espacios como lugares del aprender un saber y portar un saber, respectivamente. El sujeto de la formación es, así, el sujeto de la experiencia. Docentes y estudiantes son, a partir de aquí, sujetos sociales en cuyas acciones y relaciones la escuela se objetiva, existe (Ezpeleta y Rockwell, 1985).

\subsubsection{Les estudiantes de la escuela de artes y medios}

Voy a plantear a la cultura como una nube. Todas las nubes son distintas, y si las observamos están en cambio constante. Puede que si seguimos a una con la mirada la reconozcamos a pesar de sus cambios, también si no la miramos por un tiempo puede que la perdamos de vista y no podamos reconocerla. Las nubes cambian todo el tiempo, tanto por el viento, el tiempo. A veces surgen nuevas nubes por la evaporación del agua de lo que alguna vez fueron nubes. Las nubes pueden chocarse con otras nubes y unificarse, o cambiar completamente su forma, también las nubes pueden convertirse en lluvia, y empaparnos. A fin de cuentas las nubes están en constante cambio, como las culturas.

Lucas, $3^{\circ}$ año. Definición de cultura, junio de 2015

Me detengo unos momentos en los y las estudiantes de esta escuela y en los modos en que transitaron la jornada completa en los años a los que hace referencia este trabajo. Si bien las exigencias de la doble escolaridad podrían representar cierto agotamiento, el tiempo escolar generaba en muchos y muchas fuertes lazos de pertenencia identitaria. La escuela fue un ámbito constante de socialización en el espacio público. Un territorio de disputa signado por relaciones activas e intersubjetivas de los sujetos pedagógicos en los ámbitos heterogéneos que caracterizan a la vida cotidiana (Padawer, 2010). Jóvenes que han construido un conocimiento propio sobre los espacios y los tiempos escolares de gran magnitud. Una escuela en obra, con un patio lleno de escombros, con plagas de palomas y aulas donde llovía, generaba grandes intersticios para introducirse.

Jóvenes nacidos en democracia que desafían un espacio escolar construido desde la alteridad del mundo adulto (Kantor, 2008); desafíos que se cristalizan en un conjunto de significados acerca de la institución y lo instituido, los profesores y profesoras, los contenidos de la enseñanza, el uso de los espacios y los tiempos. Las escaleras de emergencia inhabilitadas por maderas cruzadas, los baños y sus "conexiones" (paredes astilladas, agujeritos), los momentos en que se otorga la palabra para alguna devolución de una evaluación o los contenidos dados, son todos ejemplos de cómo los y las estudiantes construían cotidianamente su experiencia escolar en un proceso constante y siempre renovado de reapropiación y reinvención de la experiencia vivida (Rockwell, 2011).

Lo único prescripto, entonces, en la escuela y en las aulas, es la permanente irrupción de la novedad, la sucesión de acontecimientos del orden de lo imprevisible. Siguiendo a Rockwell, para comprender el vínculo entre lo que se enseña y lo que se aprende, debemos examinar lo que sucede en los intersticios que encontramos en el quehacer cotidiano, "pequeños sucesos aparentemente inconexos, aparentemente prescindibles que se ubican en procesos más profundos y continuos que caracterizan a la relación educativa en las escuelas" (2011: 30). El cómo enseñar no puede estar desvinculado del qué se enseña y quiénes son los destinatarios de nuestra práctica. 


\section{Compartir la cultura}

El contexto de la institución permitiría así un abordaje más que interesante con los contenidos del Plan de Estudios vigente, por lo menos hasta la implementación de la NES que, como ya he mencionado, tuvo un impacto a todas luces negativo. No obstante, la institución se encontraba con algunas dificultades para el sostenimiento de las trayectorias escolares de algunos y algunas estudiantes. Aunque el proyecto educativo propugnaba fuertemente por la inclusión, en sus primeros años la institución terminaba siendo "expulsora" de chicos y chicas que no accedían a cierto capital cultural. Es posible que la búsqueda denodada por una escuela pensada como novedosa, en términos pedagógicos, no lograra en el camino incorporar esas otras realidades que también formaban parte de la escuela. Por otro lado, y conjuntamente con la construcción -en 2013 egresó la primera cohorte-, fue necesario comenzar a desnaturalizar cierto imaginario construido acerca del "perfil del egresado" y su inserción en el mundo universitario. De alguna manera, esos imaginarios tallaban en muchos de los y las docentes e incluso algún directivo que tomaban la escuela como un símil de los estudios superiores. Si bien es cierto que en la escuela los y las estudiantes egresaban con un bagaje teórico-conceptual más que interesante en relación con otras instituciones del nivel, ese "repensar" supuso y aún supone grandes desafíos que tienen que ver con la permanente necesidad de revisar, revisitar y volver a pensar las actividades y los textos año a año. No dar por sentadas determinadas cosas, poder mantener cierto registro de los diferentes grupos que comienzan a formar parte de la experiencia escolar y tener en cuenta el acceso diferencial a ese capital cultural legitimado es crucial, así como también la adecuación de los contenidos en función de estas variables.

Un fuerte trabajo de los equipos de la escuela que visibilizaron estas situaciones supuso volver a pensar no solo en los contenidos y las estrategias de enseñanza sino también en las representaciones que teníamos de nuestros y nuestras estudiantes y nuestro rol como educadores y educadoras. Haber constatado esta realidad, y poner sobre la mesa el tema de la calidad educativa, tan en boga en estas épocas puede, al mismo tiempo, permitirnos pensar y dar lugar a otras formas de trabajar el contenido en una institución cada vez más amplia, signada por este nuevo escenario y las tensiones y transformaciones que estas nuevas realidades suscitan. 


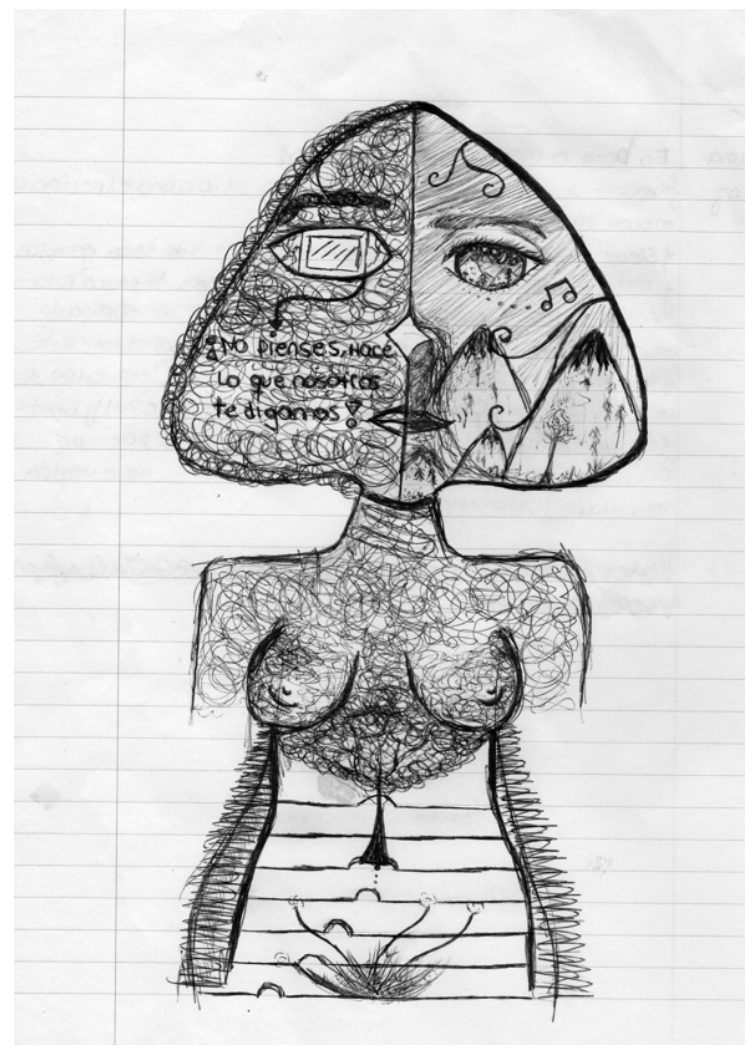

Imagen 4. Evaluación de una estudiante de $4^{\circ}$ año, 2015

Esta imagen fue el resultado imprevisto de una actividad: se proponía al alumnado que registrasen, aprovechando un contexto particular por el que estábamos atravesando como escuela, experiencias, situaciones, mecanismos, dispositivos y discursos, en donde pudieran ver reflejados los contenidos vistos en clase vinculados al concepto de poder. No hubo registros y la evaluación no fue respondida. En su lugar, sugestivamente (o no) se incorporó un dibujo con la siguiente inscripción en su rostro: "No pienses, hacé lo que nosotros te digamos!"

Inseparable entonces fue pensar en dispositivos y estrategias que abrieran un escenario múltiple y complejo de relaciones posibles frente, enfrente y al lado de los procesos educativos. Como afirma Candela, el aprendizaje es una actividad comunitaria. Si el "conocimiento escolar" se expresa y articula en la trama de relaciones que se establecen entre el docente y los alumnos en el salón de clase, cuando las cosas verdaderamente suceden, lo que sucede es "un compartir la cultura" (Bruner, 1986, cit. por Candela, 2001: 174).

\section{Conclusiones}

Este trabajo no ha sido otra cosa que el trabajo de un etnógrafo. Con dificultades, buceé en mi memoria, en las carpetas que todavía conservo, lamenté haber tirado algunas evaluaciones que fotocopié, que en alguna u otra ocasión perdí o simplemente tiré por "acumulación de papeles". Intenté, a partir de esta mirada retrospectiva, preguntarme críticamente sobre muchas de las cuestiones que tienen el vilo a la escuela secundaria -con un sino explícito de melancolía-. La gestión y la toma de decisiones, la apuesta por la educación pública y el rol docente como rol político, los supuestos desde los 
cuales partimos cuando emprendemos nuestra labor cotidiana, el sujeto de enseñanza/ sujeto de experiencia, la construcción del conocimiento, la identidad real vs la identidad prescripta, las complejidades del trabajo colectivo y nuestra frágil humanidad. En todos los procesos educativos se producen, transmiten y negocian sentidos y saberes (legítimos o legitimados, subalternos o sometidos). Los y las docentes llegamos a las aulas también con nuestros deseos, con nuestros anhelos, con nuestros esquemas de pensamiento. Detenernos a pensar en ello, al menos por un momento, supone restituir humanidad a nuestra cotidianeidad, lo que no es excusa para desentendernos de la responsabilidad del lugar que ocupamos.

Entender la escuela como un espacio donde se despliegan multiplicidad de prácticas resulta interesante a la hora de situar las específicamente pedagógicas. En este sentido, es importante decir que la matriz en la que se enseña y aprende en la escuela secundaria es, a todas luces, compleja. Multitud de dimensiones se entrelazan en días más o menos agotadores, más o menos tranquilos, más o menos generosos para la materialidad del cuerpo.

En los resquicios, en las grietas, en las fisuras que aparecen en el proceso de enseñanza y aprendizaje aparece todo lo bueno y todo lo malo del ser humano. En los espacios legítimos del conocimiento, en sus aciertos pero sobre todo en sus fallas, conocemos y sopesamos los procesos sociales que configuran la realidad social (Rockwell, 2011). El contexto histórico-político local, nacional y regional hace cada vez más imperiosa la necesidad de generar procesos de responsabilidad histórica, orientados a reconocer el valor de las experiencias para la construcción nacional, colectiva y personal. ${ }^{9}$ Restablecer la temporalidad en la escuela y sus componentes así como su raíz eminentemente política sigue siendo nuestro desafío al que espero, con estas reflexiones, haber podido contribuir. 


\section{Bibliografía}

" Bourdieu, P. y Passeron, J. P. (1970). La reproduction. París: Minuit.

»Candela, A. (2001). Transformaciones del conocimiento científico en el aula. En Rockwell, E. (Coord.), La escuela cotidiana (pp. 173-197). México: FCE.

»Carli, S. (2003). Educación pública. Historia y Promesas. En Feldfeber, M. (Comp), Los sentidos de lo público. Reflexiones desde el campo educativo (pp. 11-26). Buenos Aires: Noveduc.

»Dussel, I.; Brito, A. y Núñez, P. (2007). Más allá de la crisis. Visión de alumnos y profesores de la escuela secundaria argentina. Buenos Aires: Santillana.

》Ezpeleta, J. y Rockwell, E. (1985). Escuela y clases subalternas. En Cuadernos Políticos, 37, pp. 70-8o.

» Foucault, M. (1975). Vigilar y castigar. Nacimiento de la prisión. México: FCE.

"Foucault, M. (2000). Defender la sociedad. Buenos Aires: FCE.

"Gramsci, A. (2003). El materialismo histórico y la filosofía de Benedetto Croce. Buenos Aires: Nueva Visión.

» Grimson, A. y Tenti Fanfani, E. (2014). Mitomanías de la educación argentina. Crítica de las frases hechas, las medias verdades y las soluciones mágicas. Buenos Aires: Siglo XXI.

» Halbwachs, M. (1938). Introducción. En Durkheim, E., L'évolution pédagogique en France (pp. 4-7). París: Alcan.

» Kantor, D. (2008). Variaciones para educar adolescentes y jóvenes. Buenos Aires: Del Estante.

»Larrosa, J. (2014). Experiencia y alteridad en educación. En Skliar, C. y Larrosa, J. (Comps.), Experiencia y alteridad en educación (pp. 13-44). Rosario: FLACSO-Homo Sapiens.

" Margulis, M. (2008). La juventud es más que una palabra. Ensayos sobre cultura y juventud. Buenos Aires: Biblos.

"Montesinos, P.; Schoo, S. y Sinisi, L. (2009). Sentidos en torno a la "obligatoriedad" de la educación secundaria. Serie La Educación en debate. Documentos de la DiNIECE. Buenos Aires: Ministerio de Educación.

» Mosès, S. (1992). El Ángel de la historia. Madrid: Seuil.

»Narotzky, S. (2004). Una historia necesaria: ética, política y responsabilidad en la práctica antropológica. Relaciones. Estudios de Historia y Sociedad, Ética y política en el quehacer antropológico, XXV (98), pp. 107-145.

"Neufeld, M. y Wallace, S. (1999). Antropología y Ciencias Sociales. De elaboraciones históricas a herencias no queridas a propuestas abiertas. En Antropología social y política (pp. 37-58). Buenos Aires: Eudeba.

"Nicastro, S. (2006). Revisitar la mirada sobre la escuela. Buenos Aires: Homo Sapiens.

"Padawer, A. (2010). Tiempo de estudiar, tiempo de trabajar: la conceptualización de la infancia y la participación de los niños en la vida productiva como experiencia formativa. En Horizontes Antropológicos 16 (34), pp. 349-375. 
"Puiggrós, A. (1994). Imaginación y crisis en la educación latinoamericana. Buenos Aires: Aique.

» Rockwell, E. (2011). Los niños en los intersticios de la cotidianeidad escolar ¿Resistencia, apropiación o subversión? En Batallán, G. y Neufeld, M. R. (Coords.), Discusiones sobre infancia y adolescencia: niños y jóvenes, dentro y fuera de la escuela (pp. 27-51). Buenos Aires: Biblos.

» Romero, C. (2009). Escuela, melancolía y transición. En Romero, C. (Comp.), Claves para mejorar la escuela secundaria (pp. 19-39). Buenos Aires: Novedades Educativas.

»Rúa, M. (2016). Las prácticas de escritura: entre conocimiento, saber y contenido. Runa, 37 (1), pp. 105-121.

» Salinas, D. (1994). La planificación de la enseñanza: ¿técnica, sentido común o saber profesional? En Angulo, F. y Blanco, N. (Coords.), Teoría y desarrollo del currículum (pp. 135-160). Málaga: Aljibe.

"Sinisi, L.; Cerletti, L. y Rúa, M. (2016). La enseñanza de la Antropología y la formación de profesores. En Cerletti, L. y Rúa, M. (Comps.), La enseñanza de la Antropología (pp. 31-46). Colección Libros de cátedra. Editorial de la FFyL, UBA.

» Tenti Fanfani, E. (2003). Educación media para todos. Los desafíos de la democratización del acceso. Buenos Aires: Altamira.

» Tenti Fanfani, E. (2012). Hacia una sociología histórica de la educación. Curso Los desafíos actuales de una educación transformadora: Pensando con Bourdieu hoy. Argentina: Centro Redes/CONICET.

» Terigi, F. (2004). La enseñanza como problema político. En Frigerio, G. y Diker, G. (Comps.), La transmisión en las sociedades, las instituciones y los sujetos. Un concepto de la educación en acción (pp. 191-2014). Buenos Aires: Novedades Educativas.

\section{Gabriela Nacach}

Doctora de la Universidad de Buenos Aires, área Antropología. Profesora de Enseñanza Media y Superior en Ciencias Antropológicas. Licenciada en Ciencias Antropológicas, Universidad de Buenos Aires. Máster Europeo en Estudios Latinoamericanos, Universidad Autónoma de Madrid. Adscripción laboral actual: Profesora de Enseñanza Media y en la Formación Docente, Gobierno de la Ciudad de Buenos Aires. gnacach@gmail.com 